\title{
O Modelo do Índice de Satisfação do Cliente Norte- Americano: um Exame Inicial no Brasil com Equações Estruturais
}

\author{
André Torres Urdan \\ Arnaldo Rocha Rodrigues
}

\begin{abstract}
RESUMO
Fornell et al. (1996) propuseram e têm aplicado o Modelo do Índice de Satisfação do Cliente Norte-Americano (ISCN). Este artigo relata uma pesquisa destinada a verificar empiricamente o ajustamento de tal modelo no caso de clientes da indústria automobilística brasileira, usando-se para a análise equações estruturais. Foram obtidos dados de 304 clientes proprietários de veículos da Fiat, Ford, General Motors e Volkswagen, mediante consulta a 7 concessionárias de Belo Horizonte, MG. Considerando-se o modelo como um todo e nos limites da amostra ora utilizada, tudo parece indicar que ele padece de desajustamento, o que traz duas implicações cruciais. De um lado, há a perspectiva de que testes estatísticos podem ser uma ferramenta algo pobre para escolher um modelo: a rejeição estatística não inviabilizaria a utilização prática. De outro lado, uma abordagem mais purista levaria à rejeição do modelo ISCN, na forma como ele está estabelecido, para o ramo focado. Qualquer que seja a escolha, seria ótimo futuramente vir a ter um índice brasileiro de satisfação do cliente, com enormes benefícios potenciais para clientes e produtores.
\end{abstract}

Palavras-chaves: modelo; índice; satisfação do cliente; Estados Unidos; Brasil.

\begin{abstract}
Fornell et al. (1996) have proposed and applied the model of the American Customer Satisfaction Index (ACSI). This article reports a research undertaken to empirically test the adjustment of that model with the clients of the Brazilian automobile industry using structural equation modeling. In a survey, using the internal record of 7 dealerships in Belo Horizonte, MG, data were collected from 304 clients, comprising owners of cars manufactured by Fiat, Ford, General Motors and Volkswagen. Taking the model as a whole and in the limits of the sample generated, everything seems to indicate that it suffers from lack of adjustment, which brings two fundamental implications. On the one hand, there is the perspective stating that statistical tests may be a rather poor tool to choose a model, and as such statistical rejection would not prevent practical. On the other hand, a more purist approach would lead to the rejection of the ACSI model, as it is now designed, in the context of the industry examined. No matter the option chosen, it would be great to count with a brazilian index of customer satisfaction in the future, which could provide great potential benefits to clients and suppliers.
\end{abstract}

Key words: model; index; customer satisfaction; United States; Brazil. 


\section{Satisfação do Cliente, Antecedentes e Conseqüentes}

Numa economia de mercado, os consumidores, pelos seus votos de compra, determinam que bens e serviços devem ser providos e em quais quantidades. Itens que não são desejados sofrem queda de preços, enquanto itens desejados e produzidos em quantidade insuficiente experimentam alta de preços (Baumol e Blinder, 1982). Este mecanismo, de forma bem simples, é o que se chama soberania do consumidor. Há graus variados de soberania do consumidor no mundo real (Fulop, 1967). Quanto mais competitivo o mercado, mais forte o poder do consumidor; mais próximo de um monopólio, mais o consumidor está à mercê do fornecedor. Logo, esse grau de soberania é primordialmente determinado pela disponibilidade de alternativas de fornecedores. Onde a competição é alta, desponta a relevância do marketing, com suas definições invariavelmente enfatizando o consumidor, numa visão dos negócios como alicerçados na satisfação dele (Drucker apud Boyd Jr. e Massy, 1972).

A competição tem crescido muito no Brasil nesta década em muitos ramos, em virtude de tendências como maior abertura ao exterior, quebra de monopólios e o baixo ritmo de crescimento econômico, tornando as oportunidades mais disputadas. Em sintonia, vem avultando o papel do marketing, refletido em crescente atenção acadêmica para a compreensão da satisfação do cliente, seus antecedentes e conseqüentes, como alguns dos conceitos mais básicos dessa vasta disciplina. Basta passar os olhos nos Anais da Área Temática de Marketing do XXI ENANPAD (1997), por exemplo. Levando-se em conta apenas o título, lá havia : (1) quatro artigos sobre satisfação do cliente; (2) um artigo sobre o antecedente qualidade percebida; (3) um artigo sobre o conseqüente reclamação do cliente. Entretanto, mais do que tê-los expostos em separado ou em algumas poucas relações parciais, seria desejável ver o avanço científico ensejando concepções, contemplando com mais precisão e a um só tempo a satisfação do cliente, seus antecedentes e conseqüentes.

É a chamada elaboração teórica, em que se busca explicar um evento da forma mais abrangente e precisa possível (Selltiz, Wrightsman e Cook, 1976). Numa teoria, a adição de suposições permite dizer mais sobre o tópico, com o resultado de explicações mais completas. Embora a elaboração de um modelo, como recurso teórico, comece por simplificações, a sucessão histórica de modelos tende a ser um progresso de complexidade, no caminho para uma abordagem mais rigorosa de sistemas tomados com limites mais amplos (Mazzon, 1978). 


\section{Modelo do Í́ndice de Satisfaçāo do Cliente Norte-Americano}

Apontando exatamente nesse rumo, Fornell et al. (1996) propuseram e têm aplicado intensamente o denominado Modelo do Índice de Satisfação do Cliente Norte-Americano (ISCN), estampado na Figura 1. Ele pretende oferecer uma base de mensuração uniforme e comparável para a satisfação global do cliente, além de apontar relações de tal construto com seus principais antecedentes e conseqüentes. Implícito no modelo está o reconhecimento de que a satisfação global do cliente não pode ser medida diretamente; sendo variável latente, requer alguns indicadores na sua mensuração. O resultado mais imediato e palpável da operacionalização desse modelo é um escore da variável latente da satisfação global do cliente; em termos genéricos, é o suficiente para comparação ao longo de organizações fornecedoras, ramos de atividades, setores e até nações.

\section{Figura 1: Modelo do Índice de Satisfação do Cliente Norte-Americano}

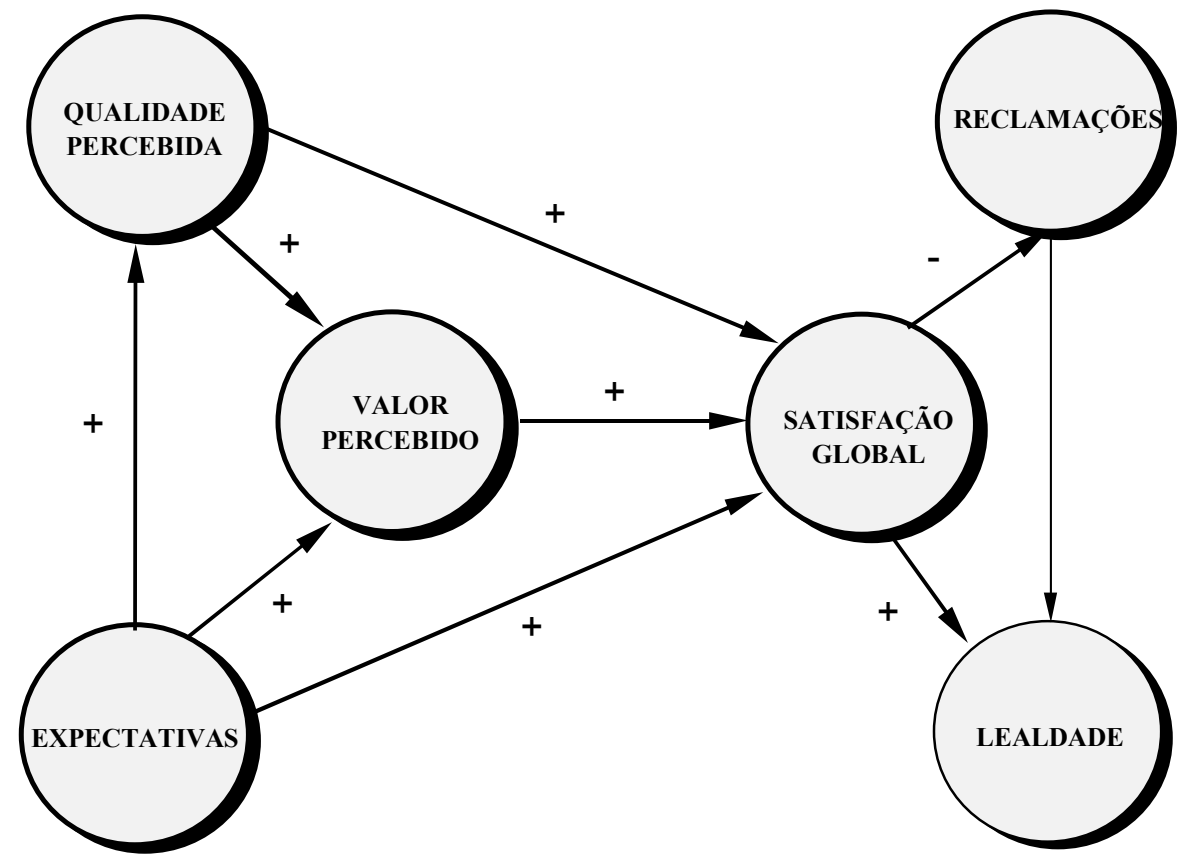

Fonte: Fornell et al. (1996, p. 8). 
Segue aqui uma descrição das relações que conformam tal modelo. A satisfação global do cliente, no centro dele, é ligada a seus: (1) antecedentes, como expectativas, qualidade percebida e valor percebido pelo cliente; (2) conseqüentes, como reclamações e lealdade. De especial interesse no modelo é a explicação da lealdade do cliente, como indicador muito provável de lucratividade (Reichheld e Sasser, 1990). Com essa estrutura, o modelo permite que o índice de satisfação global do cliente seja testado sob o ponto de vista nomológico, como o grau em que um construto se comporta como predito dentro de um sistema de construtos relacionados, na chamada rede nomológica (Cronbach e Meehl, 1955).

No modelo, a qualidade percebida está entre os determinantes da satisfação global do cliente, como a avaliação do mercado servido sobre a experiência recente de consumo. Supõe-se que a qualidade percebida tem efeito direto e positivo sobre a satisfação global. A operacionalização da qualidade percebida envolve dois componentes básicos: (1) customização, como o grau em que a oferta do fornecedor é adequada para atender às necessidades heterogêneas dos clientes; (2) confiabilidade, como o grau em que se pode contar com a oferta do fornecedor, livre de falhas e deficiências.

Um segundo determinante da satisfação global é o valor percebido. Este é o nível percebido de qualidade do produto em relação ao preço pago. Incorpora-se ao valor percebido o fator preço, que reforça a comparabilidade de resultados entre fornecedores, ramos de atividades e setores. Supõe-se haver uma associação positiva entre valor percebido e satisfação global.

As expectativas compõem o último determinante da satisfação global do cliente. As expectativas exprimem tanto a experiência prévia de consumo do cliente com a oferta do fornecedor (incluindo informações não experienciais, de fontes como propaganda e comunicação boca-a-boca), como uma previsão da habilidade do fornecedor em entregar qualidade no futuro. Pelo seu caráter predizente de qual deve ser a qualidade futura, supõe-se que as expectativas tenham efeito positivo sobre a satisfação global. Em acréscimo, supõe-se que as expectativas sejam positivamente relacionadas à qualidade percebida e, em decorrência, ao valor percebido, porque o conhecimento do cliente deve ser tal, que suas expectativas espelhem a qualidade corrente. Sendo em grande parte racionais as expectativas do cliente, devem refletir a capacidade do cliente de aprender com a experiência e predizer os níveis de qualidade e valor que irá receber (Howard, 1977).

Segundo a teoria de voz-saída de Hirschman (1970), as conseqüências imediatas de maior satisfação do cliente são o decréscimo de suas reclamações e o incremento de sua lealdade. Quando insatisfeito, o cliente tem as opções de sair do fornecedor (procurando fornecedor concorrente) ou verbalizar reclamações na 
tentativa de uma solução; por isso, no modelo, supõe-se que o aumento da satisfação global deve reduzir a incidência de reclamações e aumentar a lealdade do cliente.

O relacionamento final do modelo é entre reclamações do cliente e sua lealdade. A direção e o sinal desse relacionamento dependem dos sistemas de serviço ao cliente e da solução de reclamações dada pelo fornecedor (Fornell, 1992). Quando o relacionamento é positivo, a implicação é que o fornecedor foi bem sucedido em transformar um cliente que reclama num cliente leal. Quando o relacionamento é negativo, o fornecedor lidou com a situação de tal forma que a situação negativa tornou-se ainda pior, contribuindo para a perda da lealdade do cliente.

Como aplicação prática, o ISCN começou a ser periodicamente computado em 1994, com informações sobre 40 ramos de atividades, de 7 grandes setores da economia dos Estados Unidos (National Quality Research Center, 1995). Antes dele, o primeiro índice de satisfação do cliente de âmbito realmente nacional foi o Barômetro Sueco de Satisfação do Cliente (Fornell, 1992). Desenvolvido em 1989, esse barômetro sueco inclui 31 dos principais ramos de atividades daquele país. Na Alemanha, há o Deutsche Kundenbarometer, introduzido em 1993 e abrangendo atualmente 31 ramos de atividades (Fornell et al., 1996). Recentemente, a Nova Zelândia e Formosa começaram a trabalhar com índices de satisfação do cliente, ao passo que a Comunidade Européia recomendou a criação de tal tipo de índice em seus países membros (Fornell et al., 1996). Em boa dose, tais são repercussões e desdobramentos mundiais do modelo ISCN.

Afinal, dispor de tal tipo de indicador de satisfação global do cliente pode proporcionar enormes benefícios a qualquer país. Há, desde logo, um considerável obstáculo científico para que esses benefícios possam vir a ser usufruídos pelo Brasil. Sucede que o modelo ISCN, que é base para a geração do índice de satisfação global do cliente, é formado pela articulação de diversas relações; porém os testes dessas relações, ou seja, do modelo, sucederam originalmente na realidade norte-americana. Desse modo, nada se sabe da validade (condição prévia para a aplicabilidade) do modelo para ambientes outros, fora daquele país, pelo que vêm sendo desencadeadas iniciativas científicas de outras nações, visando a testar o referencial básico por ele proposto. Afigura-se premente promover a avaliação da adequação desse modelo também no Brasil, ensejando a subseqüente utilização dele entre nós para a geração do seu interessante índice. Antes de tratar disso mais especificamente, vale a pena examinar o panorama de um ramo de particular interesse acerca da satisfação do cliente. 


\section{O Ramo Automobilístico e o Cliente}

O ramo automobilístico impressiona pela sua imensa importância econômica no mundo todo e as dramáticas transformações por que vem passando no país ao longo desta década. De modo muito especial, nesse ramo avança-se para um estágio de elevada soberania do consumidor, dada a abundância de fornecedores. Para o Brasil está programado um dos maiores volumes de investimentos da indústria automobilística no globo (Magnavita, 1997). As montadoras devem investir cerca de US $\$ 17$ bilhões em alguns anos e o país logo passará a contar com 11 fábricas, passando para o sexto lugar no ranking mundial de produtores.

As vendas no Brasil cresceram 127\% entre 1992 e 1996, o que atraiu muito as empresas que operam no país e também montadoras estrangeiras (como Peugeot, Toyota, Mercedes Benz, BMW). Cada qual vem acreditando no grande potencial do Brasil, bem como na sua localização estratégica (como para vendas no Mercosul). É improvável que essas taxas elevadas de aumento da demanda interna por carros venham a continuar nos próximos anos. Com tantas montadoras instaladas, é certo que a concorrência será acirrada.

Esse quadro brasileiro de crescente competição global é muito recente e diferente. É uma onda que está sobrevindo depois de décadas de proteção de mercado, materializada na proibição de importação de veículos estrangeiros e a longa existência de apenas quatro montadoras, atuando com fábricas no Brasil (Fiat, Ford, General Motors e Volkswagen). Apesar dos avanços na abertura para o exterior, o Brasil ainda tem a economia mais fechada da América Latina (Moura, 1996). Em 1990, o país importava 4,9\% do Produto Interno Bruto (PIB), contra 15,5\% do México. Em 1995, o país passou a importar 7,2\% do PIB, contra $25,9 \%$ do México. A proteção contra o exterior tende a diminuir, incrementando ainda mais a concorrência já intensa, pelo que o embate competitivo interno e com o exterior tende a ser desafiador.

Presentes essas condições, entram em cena no ramo automobilístico, com máximo destaque, a soberania do consumidor, a sua satisfação e o marketing como um todo.

\section{Metodologia}

Diante dessa problemática situação relatada, o objetivo geral desta pesquisa ${ }^{(1)}$ foi realizar uma verificação empírica do ajustamento do modelo ISCN no contex- 
to dos clientes da indústria automobilística brasileira. Nesse desiderato reside a esperança de melhorar a compreensão do fenômeno da satisfação global do cliente e de seus antecedentes e conseqüentes, bem como das condições para mensurálos, usando o modelo ISCN.

Desenhou-se um estudo do tipo conclusivo, com descrição sistematizada de relacionamentos entre variáveis, haja vista contar-se com bom conhecimento prévio dos fenômenos estudados (Churchill, 1991); mas a pesquisa é mais um estudo de campo que um levantamento de campo (Mattar, 1993), pois não foi possível ter preocupação absoluta, em face da restrição de recursos financeiros, com a geração de grandes amostras representativas.

Formou-se a amostra a partir das grandes montadoras que estavam instaladas no Brasil em outubro de 1997, isto é, as empresas Fiat, Ford, General Motors e Volkswagen. Pediu-se a avaliação dos proprietários em relação a seus veículos, tendo-se como alvo, nos mesmos moldes de Fornell et al. (1996), as pessoas físicas na condição de proprietárias de automóveis de passeio e utilitários leves produzidos pelas montadoras em estudo, adquiridos novos de concessionárias autorizadas dentro de período de 6 meses a 3 anos.

A pretensão era obter os dados dos clientes, para cada uma das montadoras, por intermédio de duas concessionárias instaladas em Belo Horizonte, MG. Foram consultadas as concessionárias por meio das Páginas Amarelas da Lista Telefônica Oficial 1997 da cidade. A amostra acabou formada por 2 empresas da bandeira Fiat (Automax e Motorbel), 1 da Ford (Pisa), 2 da General Motors (Arthur Haas e Varella) e 2 da Volkswagen (Catalão e Mila). Destoou a Ford daquilo que se desejava para a amostra, pois só havia 2 concessionárias dela na cidade que preenchiam o requisito de tempo de existência (3 anos ou mais), a Pisa e a Clássica; esta última recusou-se a tomar parte na pesquisa. Saliente-se que um índice nacional de satisfação dos clientes requereria uma amostra representativa dos fornecedores, que atuam na economia do país, porém isso não foi por ora observado, haja vista o propósito de consumar apenas uma investigação inicial do modelo em si. Da parte de cada uma das concessionárias foram tomados 200 clientes, contra a quantidade de 250 adotada por Fornell et al. (1996), seguindose uma amostragem aleatória a partir dos registros existentes nas organizações participantes. Apesar das instruções passadas nesse sentido, a seleção acabou ficando sob a responsabilidade dos gerentes de contato em cada concessionária, $\mathrm{o}$ que pode ter provocado alguma imperfeição na aleatoriedade da extração amostral. No total, foram 1.400 clientes contactados para participar da pesquisa ( 7 concessionárias x 200 clientes de cada uma delas).

As variáveis latentes e observáveis do modelo estão no Quadro 1. No total, são 
16 variáveis observáveis. Estas foram medidas em escalas de diferencial semântico de 10 posições de resposta, rotuladas nos extremos, consideradas como de natureza intervalar, apesar das controvérsias (Malhotra, 1996). Em todas as variáveis observáveis, os respondentes foram solicitados a avaliar o veículo que possuíam. O conjunto de variáveis latentes foi lançado num questionário, acrescentando-se uma bateria de classificação sociodemográfica. Realizando-se rápido teste prévio do questionário, cumprido com proprietários típicos, não surgiram problemas de compreensão do seu conteúdo e de preenchimento.

\section{Quadro 1: Conjunto das Variáveis Latentes e Observáveis Utilizadas na Pesquisa}

\begin{tabular}{ll}
\hline \multicolumn{1}{c}{ Variável Latente } & \multicolumn{1}{c}{ Variáveis Observáveis Respectivas } \\
\hline Expectativas & Var01. Expectativa geral de qualidade do veículo. \\
& Var02. Expectativa da adequação do veículo às exigências pessoais. \\
& Var03. Expectativa de ausência de problemas com o veículo. \\
Qualidade Percebida & Var04. Avaliação geral da qualidade do veículo pela experiência vivida. \\
& Var05. Avaliação da adequação do veículo às exigências pessoais. \\
& Var06. Avaliação da ausência de problemas com o veículo. \\
Valor Percebido & Var07. Avaliação do preço pago tendo em vista a qualidade percebida. \\
Var08. Avaliação da qualidade percebida tendo em vista o preço pago. \\
Var09. Satisfação global com o veículo. \\
Var10. Grau em que o veículo superou as expectativas. \\
Var11. Avaliação da proximidade do veículo em relação a um veículo \\
ideal \\
Var12. Realização de reclamação formal contra o veículo. \\
Var13. Realização de reclamação informal contra o veículo. \\
Var14. Probabilidade de comprar outro veículo da mesma montadora. \\
Var15. Aumento de preço do veículo permitido numa nova compra. \\
Var16. Diminuição de preço do veículo exigida para uma nova compra. \\
\hline
\end{tabular}

Fonte: Fornell et al. (1996).

O levantamento dos dados deu-se por meio do método postal. O questionário seguiu acompanhado de um envelope já selado para a devolução, nele estando sobrescrito o endereço dos pesquisadores e inclusas as instruções sobre o preenchimento do questionário no domicílio e a devolução dele, também por via postal, sem qualquer despesa. Uma carta de acompanhamento, reiterando a importância da resposta, pela mesma via foi despachada aos clientes da amostra 10 dias depois, reiterando a importância da resposta. Foram aproveitados os questionários devolvidos até 3 meses após a data de remessa aos clientes. 


\section{A Técnica de Equaçóes Estruturais Adotada para a Análise}

A estratégia analítica foi calcada no método de modelagem de equações lineares estruturais, ou simplesmente equações estruturais, a qual permite avaliar a procedência estatística, a magnitude e a direção dos diversos caminhos causais que configuram o modelo ISCN. Além de oferecer excelente visão introdutória sobre tal método, Schuler (1995) destacava, pouco tempo atrás, que no Brasil ele não é ainda muito utilizado, tanto por certa complexidade, como pela carência de literatura nacional que facilite ter acesso a ele; mas arremata que o método é uma aquisição importante para os pesquisadores de marketing, pelos recursos de análise que proporciona, quando comparado com os métodos tradicionais. Conveniente, pois, expô-lo em suas linhas mestras.

Hair et al. (1995) lembram que todas as técnicas multivariadas de primeira geração (como análise discriminante ou análise fatorial) trazem a limitação comum de só poderem examinar uma relação por vez, uma única relação entre variáveis dependentes e independentes; entretanto amiúde o pesquisador enfrenta como problema um conjunto de relações interligadas, em que entra como solução o método das equações estruturais; daí ser ele qualificado como uma segunda geração de técnicas multivariadas. Trata-se de recurso extremamente poderoso, pois enseja tratamento mais sistemático e holístico de problemas de pesquisa, como no teste de modelos abrangentes, um conjunto de princípios fundamentais ou mesmo um teoria inteira.

Joreskog e Sorbom (1989) esclarecem a essência desse método. Muitos métodos das teorias e modelos nas ciências sociais e comportamentais, aí incluído o marketing, são formulados com base em conceitos teóricos, construtos não diretamente mensuráveis ou observáveis; porém é comum que uma quantidade de indicadores ou sintomas de tais construtos possa ser utilizada, com maior ou menor adequação, para estudar as variáveis teóricas. De modo amplo, há dois problemas de inferência científica nesse domínio. O primeiro envolve a mensuração. O que as mensurações observadas realmente medem? De que forma e quão bem alguém mede os tipos de coisas que precisam ser medidas? Como a validade e a fidedignidade das medidas podem ser expressas? O segundo problema refere-se às relações causais entre as variáveis e o relativo poder explicativo de tais relações. Como alguém pode inferir complexas relações causais entre variáveis que não são diretamente observáveis, mas refletidas em indicadores falíveis? Como as forças de relações latentes podem ser avaliadas? Para resolver esses dois tipos de problemas, o método de equações estruturais, na sua forma mais geral, desdobra-se em duas partes: o modelo de mensuração e o modelo estrutural. $\mathrm{O}$ modelo de mensuração especifica como as variáveis 
latentes (ou construtos) se medem em função de variáveis observáveis, e descreve as propriedades de mensuração (validade e fidedignidade) das variáveis observadas. $\mathrm{O}$ modelo estrutural especifica as relações causais entre as variáveis latentes e descreve os efeitos causais e a quantidade de variância não explicada. Como cada equação no modelo representa um vínculo causal, em vez de mera associação empírica, os parâmetros estruturais não coincidem, em geral, com os coeficientes de uma simples análise de regressão entre as variáveis observáreis. Em vez disso, os parâmetros estruturais representam características relativamente separadas, invariantes e autônomas do mecanismo que gera as variáveis observáveis. Para tanto, o método de equações estruturais requer ferramentas estatísticas baseadas nas convencionais análises de regressão e de variância, e que as transcendem.

Na verdade, tem-se um método geral de equações estruturais, dentro do qual se incluem diversos métodos particulares, com algumas variações de algoritmo. Além disso, há vários softwares comerciais no mercado, que trazem um ou alguns métodos particulares, entre os quais o pioneiro LISREL, já na sua oitava versão, é o mais conhecido deles. Nesta pesquisa optou-se pelo software AMOS (Arbuckle, 1997), que pode funcionar integrado ao software SPSS, deste aproveitando os arquivos de dados, facilitando sobremaneira o trabalho de análise. Uma razão em especial conduziu à escolha do AMOS: a sua propriedade distintiva de aceitar a falta de resposta para algumas variáveis nos registros dos respondentes (missing data), o que desde o início se cogitava inevitável no levantamento de dados por via postal e num questionário que exige considerável esforço de avaliação por parte dos respondentes. Tal recurso está implementado no software por meio do procedimento de estimativas de máxima verossimilhança.

Usando equações estruturais, a análise do modelo ISCN foi aplicada no nível do ramo automobilístico como um todo, com a agregação das medidas das variáveis para o conjunto de clientes que responderam ao questionário. Em tese, poderiam ser feitas análises no nível de cada uma das montadoras, embora para tanto fossem muito pequenas as amostras, tendo em vista os requisitos dessa técnica.

\section{Resultados Encontrados}

No levantamento de dados dos proprietários de veículos, realizado entre outubro de 1997 e abril de 1998, dos 1.400 questionários remetidos, retornaram em condições aproveitáveis 304 , numa proporção geral de retorno de $22 \%$, conforme 
anotado na Tabela 1 . Tendo em vista as dificuldades inerentes ao método impessoal de levantamento de dados adotado, entendeu-se razoável essa proporção global de retorno; todavia, para a concessionária 5, da montadora Ford, o retorno foi de somente $8 \%$, destoando em demasia das demais empresas; uma pena, pois a Ford já estava representada por uma única concessionária e para esta só foram aproveitados 15 questionários respondidos.

\section{Tabela 1: Mapa de Distribuição e Retorno de Questionários por Concessionária e Fábrica}

\begin{tabular}{cccc}
\hline $\begin{array}{c}\text { Concessionária } \\
\text { ou Fábrica }\end{array}$ & $\begin{array}{c}\text { Questionários remetidos } \\
\text { aos proprietários (A) }\end{array}$ & $\begin{array}{c}\text { Questionários devolvidos } \\
\text { pelos proprietários (B) }\end{array}$ & $\begin{array}{c}\text { Proporção de retorno de } \\
\text { questionários (C=B/A ) }\end{array}$ \\
\hline 1 & 200 & 55 & $28 \%$ \\
2 & 200 & 45 & $23 \%$ \\
3 & 200 & 53 & $27 \%$ \\
4 & 200 & 53 & $27 \%$ \\
5 & 200 & 15 & $8 \%$ \\
6 & 200 & 48 & $24 \%$ \\
7 & 200 & 35 & $18 \%$ \\
Total & $\mathbf{1 . 4 0 0}$ & $\mathbf{3 0 4}$ & $\mathbf{2 2 \%}$ \\
\hline Fiat & 400 & 108 & $27 \%$ \\
Ford & 200 & 15 & $8 \%$ \\
General Motors & 400 & 93 & $23 \%$ \\
Volkswagen & 400 & 88 & $22 \%$ \\
Total & $\mathbf{1 . 4 0 0}$ & $\mathbf{3 0 4}$ & $\mathbf{2 2 \%}$ \\
\hline
\end{tabular}

Depois disso, os dados lançados nos questionários pelos respondentes foram depurados, para sanar inconsistências de pronto detectáveis, passando-se à digitação num arquivo de dados do software estatístico SPSS for Windows (versão 6.1), em cujo módulo integrado AMOS 3.6.1 foram realizadas todas as manipulações e análises necessárias.

A configuração do modelo testado engloba um total de 43 variáveis, sendo 16 observáveis e 27 não observáveis, 22 exógenas e 21 endógenas. Contando com 136 distintos momentos amostrais e 20 distintos parâmetros por estimar, sobram 116 graus de liberdade. Constatou-se o atendimento dos requisitos para aplicação das estimativas por máxima verossimilhança: observações independentes e distribuição normal multivariada das variáveis exógenas. Seguindo-se para o processamento, a solução surgiu rapidamente, após 9 iterações. As Figuras 2 e 3 reproduzem as saídas da análise do modelo testado na forma de estimativas nãopadronizadas e padronizadas, respectivamente. Na saída da análise não-padronizada, repare-se que, por convenção: (1) próximo às setas unidirecionais são ano- 
tados os pesos de regressão; (2) próximo às variáveis exógenas são anotadas as variâncias. Por sua vez, na saída da análise padronizada: (1) próximo às setas unidirecionais situam-se os pesos de regressão padronizados; (2) próximo às variáveis endógenas situam-se as correlações múltiplas ao quadrado.

Figura 2: Saída da Análise do Modelo Testado na Forma de Estimativas Não-Padronizadas

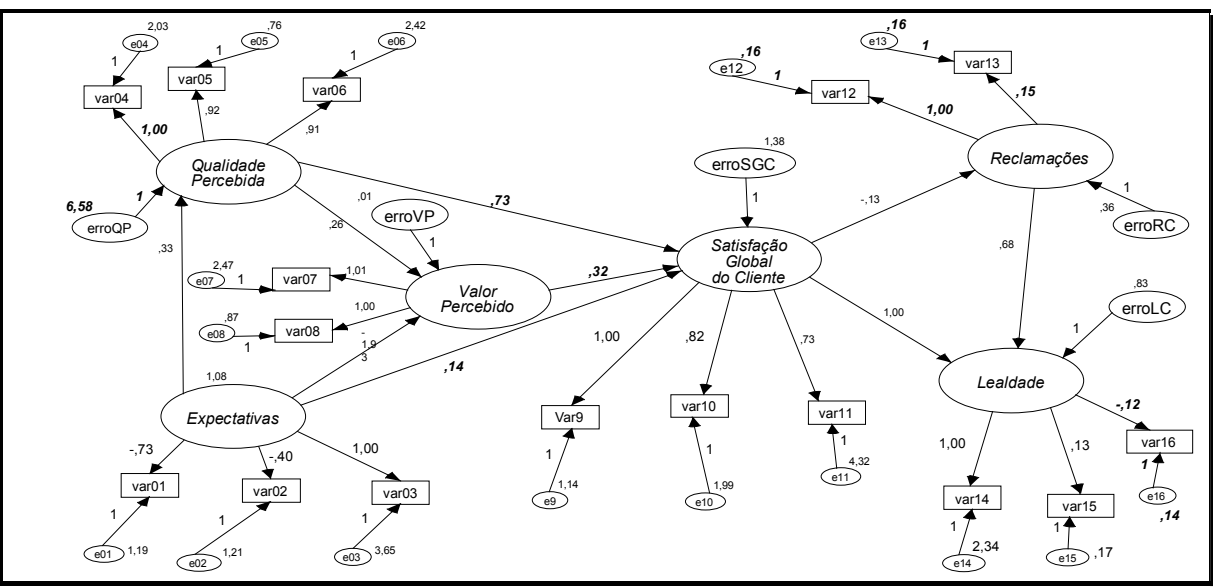

Figura 3: Saída da Análise do Modelo Testado na Forma de Estimativas Padronizadas

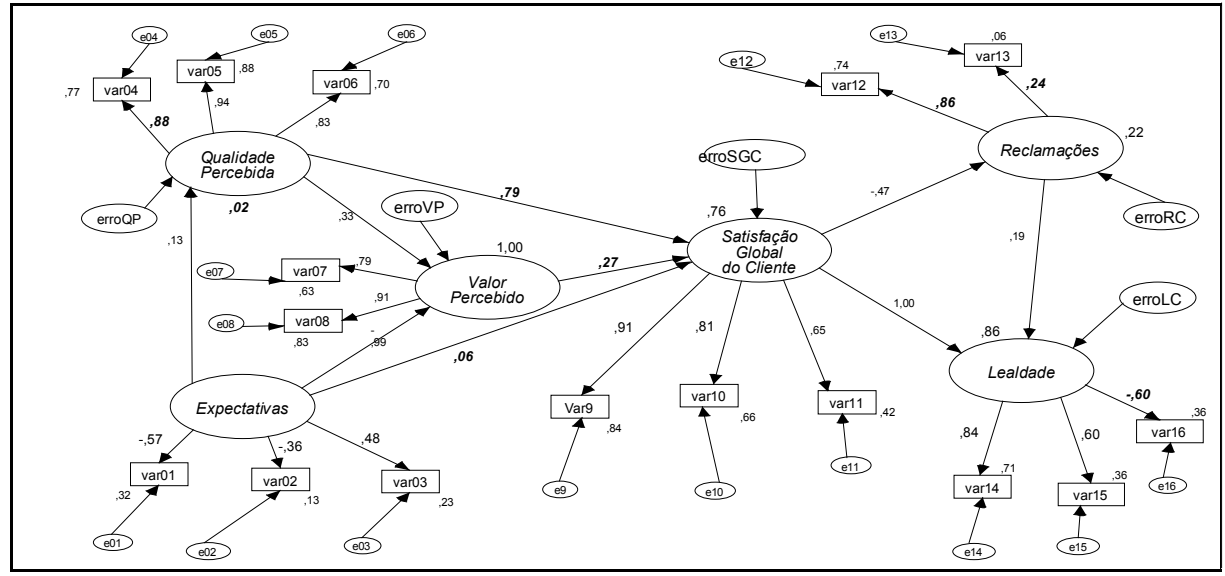


Os pesos de regressão padronizados, que são independentes das unidades em que as variáveis são mensuradas, se encontram na Tabela 2. Deixou-se de usar as estimativas não-padronizadas dos parâmetros, porque elas são de difícil interpretação, já que seus valores ficam dependentes das restrições de identificação impostas ao modelo. Tais pesos são análogos aos coeficientes beta da análise de regressão.

Tabela 2: Pesos de Regressão Padronizados dos Vínculos Causais

\begin{tabular}{|c|c|c|}
\hline \multicolumn{2}{|c|}{ Vínculo Causal } & \multirow{2}{*}{$\begin{array}{c}\text { Estimativa do } \\
\text { Peso de Regressão }\end{array}$} \\
\hline Causa & $\mid<<<------$ & \\
\hline Variável Latente & Variável Latente & \\
\hline Qualidade Percebida & Expectativas & 0,135 \\
\hline Valor Percebido & Expectativas & $-0,989$ \\
\hline Valor Percebido & Qualidade Percebida & 0,325 \\
\hline Satisfação Global & Qualidade Percebida & 0,790 \\
\hline Satisfação Global & Expectativas & 0,060 \\
\hline Satisfação Global & Valor Percebido & 0,268 \\
\hline Reclamações & Satisfação Global & $-0,469$ \\
\hline Lealdade & Reclamações & 0,191 \\
\hline Lealdade & Satisfação Global & 0,999 \\
\hline Variável Observável & Variável Latente & \\
\hline Var01 & Expectativas & $-0,569$ \\
\hline Var02 & Expectativas & $-0,358$ \\
\hline Var03 & Expectativas & 0,479 \\
\hline Var04 & Qualidade Percebida & 0,876 \\
\hline Var05 & Qualidade Percebida & 0,939 \\
\hline Var06 & Qualidade Percebida & 0,834 \\
\hline Var07 & Valor Percebido & 0,794 \\
\hline Var08 & Valor Percebido & 0,909 \\
\hline Var09 & Satisfação Global & 0,914 \\
\hline Var10 & Satisfação Global & 0,812 \\
\hline Var11 & Satisfação Global & 0,645 \\
\hline Var12 & Reclamações & 0,857 \\
\hline Var13 & Reclamações & 0,238 \\
\hline Var14 & Lealdade & 0,843 \\
\hline Var15 & Lealdade & 0,598 \\
\hline Var16 & Lealdade & $-0,601$ \\
\hline
\end{tabular}


Conforme a Tabela 2, entre as relações das variáveis latentes, somente se apresentou com sentido contrário ao previsto no modelo do ISCN o efeito de expectativas sobre valor percebido, neste caso sendo negativa a expectativa e espelhando forte vínculo (peso - 0,99 ); portanto a elevação das expectativas tem impacto inversamente proporcional ao valor percebido. Ademais, embora com o sentido previsto, pode-se interpretar que são muito leves (abaixo de 0,30 ) os pesos de regressão para os seguintes vínculos: (1) expectativas sobre qualidade percebida (peso 0,14); (2) expectativas sobre satisfação global (peso 0,06); (3) valor percebido sobre satisfação global (peso 0,27 ); (4) reclamações sobre lealdade (peso 0,19). Ao contrário, é pertinente qualificar como fortes (peso acima de $0,70)$ e no sentido previsto os vínculos adiante: (1) qualidade percebida sobre satisfação global (peso 0,80); (2) satisfação global sobre a lealdade (peso de $1,00)$.

No concernente às relações entre variáveis latentes e observáveis, ainda com alicerce no conteúdo da Tabela 2, assomam com sentido contrário ao previsto três dos vínculos: (1) expectativas sobre as variáveis V01 (peso -0,57) e Var02 (peso $-0,36$ ); (2) lealdade sobre a variável Var16 (peso - 0,60 ); como tal, numa empreitada de aprimoramento do modelo ISCN, tais variáveis seriam naturalmente indicadas para exclusão. Fora isso, dos 13 vínculos remanescentes, somente não emergem com vínculos fortes (peso acima de 0,70 ) os seguintes pares: (1) expectativas sobre a Var03 (peso 0,48); (2) reclamações sobre a Var13 (peso 0,24); (3) lealdade sobre a Var16 (peso 0,60).

A Tabela 3 traz as correlações múltiplas ao quadrado, retratando a proporção da variância de uma variável endógena, que é explicada pelas suas variáveis predizentes. Como critério de avaliação, adotou-se a sugestão oferecida por Fornell e Larcker (1981): a variância extraída deve ser pelo menos 50\%, evitando-se a situação em que haja mais erro de mensuração do que variância válida. Com esse juízo, quanto às relações entre variáveis latentes, tem-se: (1) a variância de qualidade percebida é muito insuficientemente explicada, na base de desprezíveis $2 \%$; (2) a variância de valor percebido é totalmente explicada, na base de $100 \%$; (3) a variância de satisfação global é em grande parte explicada, na base de $76 \%$, nivelado com os $75 \%$ encontrados por Fornell et al. (1996), na média dos setores da economia dos Estados Unidos; (4) a variância de reclamações é insuficientemente explicada, na base de reduzidos $22 \%$; (5) a variância de lealdade é em elevada parte explicada, na base de $86 \%$, mais que o dobro dos 36\% encontrados por Fornell et al. (1996) nas médias dos setores da economia dos Estados Unidos. 


\section{Tabela 3: Correlações Múltiplas ao Quadrado das Variáveis Endógenas}

\begin{tabular}{|c|c|c|c|}
\hline $\begin{array}{c}\text { Variável } \\
\text { Endógena }\end{array}$ & $\begin{array}{l}\text { Variáveis } \\
\text { Predizentes }\end{array}$ & $\begin{array}{l}\text { Correlação Múltipla } \\
\text { ao Quadrado (CMQ) }\end{array}$ & $\begin{array}{l}\text { Média das CMQ por } \\
\text { Variável Predizente* }\end{array}$ \\
\hline Qualidade Percebida & Expectativas & $1,8 \%$ & \\
\hline Valor Percebido & $\begin{array}{c}\text { Expectativas } \\
\text { Qualidade Percebida }\end{array}$ & $99,6 \%$ & \\
\hline Satisfação Global & $\begin{array}{l}\text { Expectativas } \\
\text { Qualidade Percebida } \\
\text { Valor Percebido }\end{array}$ & $76,2 \%$ & \\
\hline Reclamações & Satisfação Global & $22,0 \%$ & \\
\hline Lealdade & Satisfação Global & $85,6 \%$ & \\
\hline Var01 & Expectativas & $32,4 \%$ & \\
\hline Var02 & Expectativas & $12,8 \%$ & \\
\hline Var03 & Expectativas & $22,9 \%$ & $22,7 \%$ \\
\hline Var04 & Qualidade Percebida & $76,7 \%$ & \\
\hline Var05 & Qualidade Percebida & $88,2 \%$ & \\
\hline Var06 & Qualidade Percebida & $69,6 \%$ & $78,2 \%$ \\
\hline Var07 & Valor Percebido & $63,0 \%$ & \\
\hline Var08 & Valor Percebido & $82,7 \%$ & $72,9 \%$ \\
\hline Var09 & Satisfação Global & $83,5 \%$ & \\
\hline Var10 & Satisfação Global & $66,0 \%$ & \\
\hline Var11 & Satisfação Global & $41,6 \%$ & $63,7 \%$ \\
\hline Var12 & Reclamações & $73,5 \%$ & \\
\hline Var13 & Reclamações & $5,7 \%$ & $39,6 \%$ \\
\hline Var14 & Lealdade & $71,1 \%$ & \\
\hline Var15 & Lealdade & $35,7 \%$ & \\
\hline Var16 & Lealdade & $36,2 \%$ & $47,7 \%$ \\
\hline
\end{tabular}

(*) Apenas em relação às variáveis endógenas observáveis.

Já acerca das relações entre variáveis endógenas observáveis e variáveis predizentes latentes, a mesma Tabela 3 revela: (1) as variâncias de expectativas (média de 23\%), reclamações (média de 40\%) e lealdade (média de 48\%) explicam insuficientemente as respectivas variâncias de suas variáveis observáveis; (2) as variâncias de qualidade percebida (média de 78\%), valor percebido (média de 73\%) e satisfação global (média de 64\%) explicam suficientemente as respectivas variâncias de suas variáveis observáveis.

Depois de algumas avaliações por partes, cumpre examinar o ajustamento do modelo do ISCN como um todo, o que vem a ser o objetivo básico desta pesquisa. É preciso reconhecer que tal tipo de avaliação constitui uma das questões mais debatidas e difíceis no campo das equações estruturais, havendo variedade de pontos de vista e de medidas disponíveis (Bollen e Long, 1993). Na verdade, para equações estruturais não há um único teste estatístico que melhor descreva a força das predições do modelo. Logo, aqui foi selecionado um conjunto de 5 medi- 
das, entre as principais existentes, como lançado na Tabela 4, tudo com base em Hair et al. (1995) e Arbuckle (1997).

\section{Tabela 4: Medidas de Ajustamento do Modelo Testado}

\begin{tabular}{ccc}
\hline Natureza da Medida & Sigla da Medida & Valor da Medida \\
\hline Qui-Quadrado sobre Graus de Liberdade................ & $\chi^{2}$ / DF & 12,25 \\
Índice de Bondade do Ajustamento....................... & GFI & 0,53 \\
Índice de Bondade do Ajustamento Ajustado........... & AGFI & 0,44 \\
Erro de Aproximação da Raiz do Quadrado Médio & RMSEA & 0,19 \\
Índice de Tucker-Lewis........................................... & TLI & 0,48 \\
\hline
\end{tabular}

Um alto valor da medida qui-quadrado sobre graus de liberdade $\left(\chi^{2} / D F\right)$ significa que as matrizes observadas e estimadas diferem consideravelmente, razão pela qual se sugere para um bom modelo uma razão 5 ou menos. Neste caso, o $\chi^{2} / \mathrm{DF}$ atingiu a marca de 12 , sinalizando um precário ajustamento do modelo. Acerca do índice de bondade do ajustamento, medida que varia de 0 (ajustamento pobre) a 1.0 (ajustamento perfeito), não há limites consagrados de aceitação. Verifica-se neste caso que ele ficou apenas na metade do máximo $(0,5)$, o que não pode ser considerado como indicação favorável ao modelo. Já o índice de bondade de ajustamento ajustado (AGFI), como extensão da medida anterior, tem a vantagem de incorporar no seu cálculo os graus de liberdade do modelo proposto, para o qual o nível de aceitação recomendado é 0,90 ou mais. Neste caso, o AGFI situou-se em 0,4 , reforçando a indicação de que o modelo padece de precário ajustamento. O erro de aproximação da raiz do quadrado médio (RMSEA) é medido pela discrepância (uma média dos resíduos entre as matrizes estimadas e observadas), em termos da população (e não da amostra), por grau de liberdade, onde valores abaixo de 0,08 são interpretados como aceitáveis. Neste caso, o RMSEA alcançou 0,2, acrescentando mais uma indicação de desajustamento do modelo. Por fim, o índice de Tucker-Lewis (TLI) compara o modelo proposto com um modelo básico, este sendo um modelo realístico que se espera que todos os demais devam exceder, além de incorporar uma medida de parcimônia, em que o recomendável é um valor de 0,9 ou maior. Neste caso, contando-se com um TLI de 0,5 , fecha-se a relação completa de medidas, que apontam para problemas de ajustamento do modelo do ISCN no âmbito estudado. 


\section{LIMITAÇóEs, CONCLUSÓES E IMPLICAÇÓES}

Entre as diversas limitações desta pesquisa, apesar do espaço exíguo, algumas não podem ficar sem menção, haja vista sua relevância. Primeiro, os autores do modelo do ISCN vêm divulgando muito poucos dados de testes de seu modelo, cuja razão provável é o fato de ele ter-se tornado um negócio comercial cada vez maior e muito promissor; porém essa carência dificulta sobremaneira a comparação em iniciativas que pretendam, como aqui, replicar o trabalho original. Segundo, o exame original do modelo ISCN deu-se pelo critério de mínimos quadrados parciais, enquanto aqui foi empregado o critério de estimativa de máxima verosimilhança, o que envolve algumas diferenças quanto à minimização das funções de discrepância; todavia nenhum dos dois softwares disponíveis aos pesquisadores, AMOS e LISREL, inclui o critério de mínimos quadrados parciais. Terceiro, incidiu sobre a pesquisa a restrição de um erro de não-resposta dos proprietários, pois a maior parte deles, cerca de $78 \%$ (vide Tabela 1), não respondeu ao questionário: a dúvida que se instala é se aqueles que responderam diferem substantivamente daqueles que não responderam, em termos de variáveis relevantes para o estudo (Malhotra, 1996). Se a discrepância é expressiva, então as estimativas extraídas das amostras devem estar contaminadas de vieses. Quarto, tem-se aqui estudado nada mais do que um ramo de atividades, o automobilístico, dele extraindo-se uma amostra de apenas uma cidade brasileira. A superação de tais limitações deve animar quaisquer esforços futuros de investigação do problema abordado.

Apesar dessas limitações, tomando-se as partes do modelo ISCN, e sempre tendo em vista os limites da amostra estudada, importa destacar algumas conclusões expressivas, apesar das várias improcedências antes relatadas. Com base na correlação múltipla ao quadrado, sabe-se que a variância de valor percebido é totalmente explicada (100\%); a variância de satisfação global é em grande parte explicada (76\%); a variância de lealdade é em elevada dose explicada (86\%). Ademais, conforme os pesos de regressão padronizados, viu-se que são bem fortes os efeitos de qualidade percebida sobre satisfação global e de satisfação global sobre lealdade (vide Tabela 2). Tais relações podem ser encaradas como contribuições muito úteis, servindo para orientar também os praticantes de marketing e administração da indústria automobilística, em que pese o caráter não-probabilístico desta pesquisa. Se realmente a lealdade é antecedida pela qualidade percebida e pela satisfação global, o produtor que usufrui melhoria nessa relação deve ser favorecido por efeitos como menor elasticidade de preço, proteção de participação de mercado, queda dos custos de atração de novos clientes e privilegiada reputação no mercado. Por aí, a satisfação do cliente deve levar a 
desempenho financeiro superior, o que toda a organização almeja (Anderson, Fornell e Lehman, 1994; Ittner e Larcker, 1996; Fornell et al., 1996).

Considerando-se o todo, cumpre reconhecer que o modelo do ISCN padece de desajustamento na esfera da amostra considerada, o que traz duas implicações cruciais. De um lado, há a perspectiva de que os testes estatísticos podem ser uma ferramenta algo pobre para escolher-se um modelo (Arbuckle, 1997). Um modelo é sempre uma representação dos elementos mais importantes, uma condensação de um sistema do mundo real percebido (Naert e Leeflang, 1978). Por conseguinte, no melhor dos casos, modelo pode ser uma aproximação e, como tal, pode ser útil sem ser plenamente verdadeiro. Não sendo nunca perfeitos, os modelos podem ser rejeitados por critérios estatísticos, mas nem por isso se tornarem condenados para utilização. Prevalecendo esse raciocínio, não haveria por que deixar de usar o modelo ISCN, com a substantiva vantagem de permitir a mensuração da satisfação global do cliente de praticamente qualquer ramo de atividade no Brasil e tê-la comparada (benchmarking) com os níveis respectivos regularmente divulgados sobre a realidade norte-americana, a maior potência econômica do mundo.

De outro lado, uma abordagem mais purista levaria à rejeição do modelo ISCN na forma como está estabelecido para o ramo focado. Daí as opções seriam: (1) iniciar a concepção de um modelo de satisfação do cliente a partir da estaca zero, tendo por substrato as especificidades da realidade brasileira; (2) tentar modificar o modelo rejeitado de forma incremental, melhorando o seu ajustamento aos dados (Hair et al., 1995). Por este prisma, numa modalidade ou na outra, perder-se-ia a atraente possibilidade de comparação com os indicadores dos Estados Unidos.

Qualquer que seja a escolha, e elas não são excludentes, seria ótimo futuramente vir a ter um índice brasileiro de satisfação do cliente, talvez ampliando para um nível macro de abrangência aquilo que já foi proposto no país por Rossi e Slongo (1997). Na atualidade, não se pode admitir que o entendimento de uma economia esteja restrito a indicadores de quantidade e preços de serviços e bens produzidos. A economia é um todo multifacetado, em que se mostra crucial considerar também as medidas da qualidade, valor e satisfação atribuídas pelos clientes à produção que consomem. Um indicador de satisfação do cliente pode muitíssimo ajudar os próprios clientes, pela melhoria das decisões de compra, pois o comprador passa a dispor de informações confiáveis e precisas. Abre-se caminho, assim, para o consumo de bens e serviços de melhor qualidade e/ou valor, dentro das expectativas do cliente, o que tende a culminar com o aprimoramento do padrão geral de vida da população, ainda que mantidos os níveis de renda da sociedade. É previsível que a mera existência de um índice independente de satisfação do cliente induza esforços dos produtores de bens e serviços para apurar suas ofertas, 
enraizando na gestão deles maior apreço pelos clientes e suas avaliações, criando genuína mentalidade de marketing. De fato, seria de enorme utilidade dispor de metodologia uniforme e independente de avaliação, sob a ótica do cliente, daquilo que é produzido e consumido no país. Ainda que leve muito tempo para a consolidação de tal índice, espera-se que a iniciativa exposta, mesmo sendo de mínima envergadura, possa estimular esforços adicionais de pesquisa nesse rumo tão promissor.

Impõe-se ter em mente que a adoção de modelos requer critérios. Na administração em geral, e no marketing em particular, parece haver uma inclinação muito maior a propor modelos do que a testá-los. Uma das razões bem provável desse prejudicial desequilíbrio de atenção deve estar no meticuloso trabalho envolvido num teste empírico, em geral bem mais árduo (também menos empolgante) do que o demandado pela proposição, pura e simples, de mais um modelo; todavia a avaliação empírica de um modelo é imprescindível para sugerir as modificações que se devem introduzir para se dispor de modelos mais realistas. Daí a necessidade premente de empreender mais pesquisas sobre o tema tratado.

\section{Nota}

${ }^{1}$ Trabalho realizado com bolsas do Conselho Nacional de Desenvolvimento Científico e Tecnológico (CNPq), a quem fica registrada a gratidão dos autores.

\section{ReFERENCIAS BibLIOGRÁfiCAS}

ANDERSON, E. W.;

FORNELL, C.;

LEHMAN, D. R.

Customer satisfaction, market share, and profitability : findings from Sweden. Journal of Marketing, v. 58, n. 1, p. 53-66, Jan. 1994.

ARBUCKLE, J. L.

AMOS user's guide - version 3.6. Chicago : SPSS, 1997.
BAUMOL, W. J.;

BLINDER, A. S.

Economics : principles and policy. New York : Hartcourt Brace Jovanovich, 1982.

BOLLEN, K. A.;

LONG, J. S.

Testing structural equation models. London : Sage Publications, 1993. 
BOYD JR., H. W.;

MASSY, W. F.

Marketing management. New York : Harcourt Brace Jovanovich, 1972.

CHURCHILL, G. A. Marketing research : methodological foundations. Fort Worth : Dryden Press, 1991.

CRONBACH, L. J.;

MEEHL, P. E.

Construct validity in psychological tests.

Psychological Bulletin, v. 52, n. 4, p. 281-302, 1955.

XXI ENCONTRO DA ASSOCIAÇÃO NACIONAL DOS PROGRAMAS DE PÓS-GRADUAÇÃO EM ADMINISTRAÇÃO.

(1997 : Angra dos Reis). Anais Eletrônicos... Rio de Janeiro : ANPAD, 1997.

FORNEL, C.

A national customer satisfaction barometer : the Swedish experience. Journal of Marketing, v. 56, n. 1, p. 06-21, Jan. 1992.

FORNELL, C.;

LARCKER, D. F.

Evaluating structural equation models with unobservable variables and measurement error. Journal of Marketing Research, v. 18, n. 1, p. 39-50, Feb. 1981.
FORNELL, C. et al.

The American customer satisfaction index : nature, purpose, and findings. Journal of Marketing, v. 60, n. 4, p. 07-18, Oct. 1996.

FORNELL, C.;

ITTNER, C. D.;

LARCKER, D. F.

The valuation consequences of customer satisfaction across industries. Working paper, Ann Arbor, National Quality Research Center, 1996.

FULOP, C.

Consumers in the market : a study in choice, competition and sovereignty. London : The Institute of Economic Affairs, 1967.

HAIR, J. F. et al.

Multivariate data analysis with readings. London : Macmillan, 1995.

HIRSCHMAN, A. O.

Exit, voice, and loyalty responses to decline in firms, organizations, and states. Boston, MA : Harvard University Press, 1970.

HOWARD, J. A.

Consumer behavior : application of theory. New York : McGrawHill, 1977. 
ITTNER, C. D.;

LARCKER, D. F.

Measuring the impact of quality initiatives on firm financial performance. In: GHOSH, S.; FEDOR, D. Advances in the management of organizational quality. Greenwich : Jay Press, 1996. v. 1.

JORESKOG, K. G.;

SORBOM, D.

LISREL 7: a guide to the program and applications. 2. ed. Chicago : SPSS, 1989.

MAGNAVITA, M.

Fábricas de carros devem investir US\$17 bilhões. O Estado de São Paulo, 27 maio 1997.

MALHOTRA, N. K.

Marketing research : an apllied orientation. Englewood Cliffs, NJ: Prentice-Hall, 1996.

MATTAR, F. N.

Pesquisa de marketing : metodologia, planejamento, execução e análise. São Paulo : Atlas, 1993. v. 2.

MAZZON, J.

Formulação de um modelo de avaliação e comparação de modelos em marketing. São Paulo, 1978. Dissertação (Mestrado) Faculdade de Economia, Administração e Contabilidade, Universidade de São Paulo.
MOURA, G. C.

Uma economia aberta, mas nem tanto. O Globo, Rio de Janeiro, 18 de nov. 1996. Caderno de Economia, p. 17.

NAERT, P. A.;

LEEFLANG, P. S. H.

Building implementable marketing models. Leiden : Martinus Nijhoff, 1978.

NATIONAL QUALITY RESEARCH CENTER.

American customer satisfaction index : methodology report. Milwaukee : American Society for Quality Control, 1995.

REICHHELD, F. F.;

SASSER, W. E.

Zero defections : quality comes to services. Harvard Business Review, v. 68, n. 5, p. 105-11. Sept./Oct. 1990.

ROSSI, C. A. V.;

SLONGO, L. A.

Pesquisa de satisfação de clientes: o estado-da-arte e proposição de um método brasileiro. In: XXI ENCONTRO ANUAL DA ANPAD (1997 : Angra dos Reis). Anais Eletrônicos... Rio de Janeiro : ANPAD, 1997.

SCHULER, M.

Análise multivariada de segunda geração : tudo o que eu queria saber sobre Lisrel e que os matemá- 
ticos foram herméticos demais para me explicar. Revista Brasileira de Administração Contemporânea, v. 1, n. 5, p. 93-108, set. 1995.
SELLTIZ, C.;

WRIGHTSMAN, L. S.;

COOK, S. W.

Research methods in social relations. New York : Holt, Rinehart and Winston, 1976. 